\title{
Você, eu e nós: o compartilhamento de experiências emocionais
}

\section{You, Me and We: The Sharing of Emotional Experiences}

DOI: http://dx.doi.org/10.12957/ek.2014.15182

Prof. Dr. Dan Zahavi

dza@hum.ku.dk

University of Copenhagen -

tradução Gabriel Henrique Dietrich

Dinamarca

dietrichgabriel@gmail.com

$\mathrm{Na}$ presente contribuição, meu objetivo primário será oferecer uma resposta para a seguinte questão: a experiência do nós, a experiência de ser parte de um nós, pressupõe, precede, preserva ou abole a diferença entre a experiência de si e a experiência do outro? Ao empreender esta tarefa, olharei com mais proximidade para o compartilhamento emocional e me basearei em recursos que são também com frequência ignorados na atual ontologia social, a saber, insights encontrados na fenomenologia clássica e na pesquisa contemporânea sobre cognição social.

\section{PALAVRAS-CHAVE}

compartilhamento emocional. intencionalidade coletiva. intencionalidade-eu. intersubjetividade

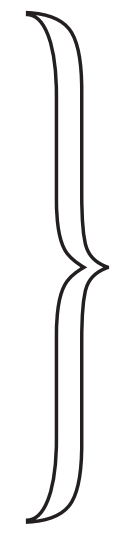

In the present contribution, my primary aim will be to offer an answer to the following question: does the we-experience, the experience of being part of a we, presuppose, precede, preserve, or abolish the difference between self- and other-experience? In pursuing this task, I will take a closer look at emotional sharing and draw on resources that are too frequently ignored in current social ontology, namely insights found in classical phenomenology and in contemporary research on social cognition.

\section{KEY-WORDS emotional sharing. collective intentionality.}

* Texto publicado originalmente em: Zahavi, D. (2015) You, Me, and We: The Sharing of Emotional Experiences, Journal of Consciousness Studies, 22 (1-2), pp. 84-101. O corpo editorial da revista Ekstasis agradece a resposta e amável sugestão de publicação desse texto feita pelo Prof. Dan Zahavi, assim como ao editor Graham Horswell da $J C S$ pelos direitos gentilmente cedidos para a publicação da presente tradução. 
Quando se examina o trabalho filosófico recente sobre a natureza e o status da intencionalidade coletiva e das intenções-nós (we-intentions), é notável quanto esforço é posto em analisar a estrutura da ação conjunta e em estabelecer se a intenção, por exemplo, de sair para caminhar junto ou de pintar uma casa juntos é redutível a alguma forma de intencionalidade-eu (I-intention). Muito menos trabalho tem sido devotado a uma análise dos afetos e emoções compartilhados. Isso é lamentável não apenas porque o compartilhamento emocional parece ser, muito provavelmente, em termos desenvolvimentais, anterior a e logicamente mais básico que a ação conjunta, mas também porque ele poderia constituir um modo de estar junto com outros que nós necessitamos estudar, se nós desejamos compreender a natureza do nós.

Na presente contribuição, meu objetivo primário será oferecer uma resposta para a seguinte questão: a experiência do nós, a experiência de ser parte de um nós, pressupõe, precede, preserva ou abole a diferença entre a experiência de si e a experiência do outro? Ao empreender esta tarefa, olharei com mais proximidade para o compartilhamento emocional e me basearei em recursos que são também com frequência ignorados na atual ontologia social, a saber, insights encontrados na fenomenologia clássica e na pesquisa contemporânea sobre cognição social.

\section{Intencionalidade coletiva e intersubjetividade}

De acordo com uma perspectiva atualmente dominante, embasada tanto por argumentos filosóficos quanto por evidência empírica, a capacidade de ter intenções-nós (we-intentions) é fundamental para a vida social humana e para a realidade social (por exemplo, institucional). É um pré-requisito crucial para a criação e manutenção de normas sociais, convenções, e fatos institucionais, tais como eleições, casamentos, corporações, direitos de propriedade, estados nações etc. A coordenação social complexa pode não ser exclusiva para humanos - várias espécies de animais não-humanos se vinculam a formas de comportamento cooperativo (por exemplo, caçar juntos) - mas, como Searle argumentou, humanos parecem possuir uma capacidade para uma forma específica de intencionalidade coletiva ou compartilhada que permite-lhes criar formas de realidade social que de longe excedem aquelas que podem ser obtidas por primatas não-humanos (SEARLE, 1995).

A própria investigação altamente influente de Searle da intencionalidade coletiva permanece comprometida com uma forma de individualismo metodo- 
lógico e ontológico. O individualismo ontológico afirma que estados mentais são necessariamente próprios (owned), que eles são necessariamente estados de alguém, e este alguém tem de ser um indivíduo. Em resumo, apenas indivíduos podem ser sujeitos de estados mentais. Searle consequentemente afirma que toda intencionalidade, e isso inclui intencionalidade coletiva, deve ser atribuída a e localizada nas mentes de indivíduos singulares. Assim, sempre que pessoas compartilhem uma intenção, cada indivíduo tem sua própria intenção, e não há algo assim como uma intenção (emblemática [token]) que seja compartilhada, em qualquer sentido simples do termo. Isso não é dizer, entretanto, que Searle tenta reduzir intenções-nós (we intentions) a intenções-eu (I-intentions). Em seu artigo seminal, "Intenções coletivas e ações", de 1990, Searle explicitamente rejeita esta ideia e ao invés disso defende a perspectiva de que intenções-nós são primitivas (Searle, 1990, 404). Mas ele também nega que deva haver qualquer incompatibilidade entre a afirmação de que intenções-nós são irredutíveis e a afirmação de que toda intencionalidade existe em mentes individuais. De fato, dado o endosso bastante conhecido de Searle ao internalismo e seu comprometimento com a perspectiva de que nenhum estado psicológico pressupõe a existência de nenhum outro indivíduo que não seja o sujeito para o qual o estado é atribuído, ele inclusive argumenta que um indivíduo pode intencionar-nós (we-intend) mesmo que outro agente não exista. Searle consequentemente concede a intencionalidade-nós em termos solipsistas e tem insistido que um indivíduo pode possuir intencionalidade coletiva mesmo se ele não fosse nada senão um cérebro numa cuba (SEARLE, 1990, 406-407).

Pode-se ter todo tipo de preocupações acerca do internalismo radical de Searle e sobre sua afirmação de que um indivíduo pode ter intenções-nós e possuir intencionalidade coletiva mesmo se ninguém mais existisse (cf. SCHMID, 2009), mas deixe-me focar aqui sobre um aspecto diferente e menos conhecido da teoria de Searle. Para o final de sua contribuição de 1990, Searle pergunta se há quaisquer capacidades de segundo plano (background capacities) e fenômenos que são pressupostos pela intencionalidade coletiva. Ele responde a questão na afirmativa e declara que uma das pressuposições centrais é um "sentido biologicamente primitivo de outra pessoa como um candidato para intencionalidade compartilhada" (SEARLE, 1990, 415). De modo a ter ou agir com intenções coletivas, alguém deve consequentemente supor que "outros também são agentes como ele mesmo, que eles têm uma consciência similar a sua e como um agente como eles mesmos, e que essa consciência coalesce em um sentido de nós como agentes coletivos possíveis ou efetivos" $(1990,414)$. Searle não 
desenvolve essas ideias em detalhes, mas eu as considero bastante sugestivas e, mais importante, eu penso que elas podem ser e tem sido desenvolvidas e defendidas de um modo que vai muito além do que Searle poderia ter em mente.

Em sua introdução de $A$ construção da realidade social, Searle observa que aos grandes sociólogos-filósofos do início do século XX faltaram as ferramentas adequadas, especialmente uma teoria da intencionalidade suficientemente desenvolvida, para lidar com a questão da intencionalidade-nós (weintentionality) (SEARLE, 1995, xii). Searle se refere à obra de Weber, Simmel e Durkheim, mas esquece de Schutz, cuja dissertação, Der sinnhafte Aufbau der sozialen Welt, de 1932, tem muito mais em comum com o projeto de Searle do que meramente o título. O que nós encontramos em Schutz, e em outros fenomenólogos como Husserl, Scheler, Stein, Reinach, Walther, Heidegger, Gurwitsch, Sartre e Merleau-Ponty, não são apenas análises muito sofisticadas da intencionalidade, consciência de si e dos outros e intersubjetividade, mas também uma investigação orientada para a intencionalidade-nós e seu envolvimento na constituição da realidade social. De fato, uma das contribuições que se encontra na fenomenologia é precisamente um esforço concentrado em explorar os modos nos quais indivíduos são experiencialmente interrelacionados, e basear a análise da intencionalidade coletiva sobre uma abordagem da compreensão interpessoal e do reconhecimento recíproco. Quando Searle afirma que uma coisa que ele aprendeu em sua disputa com Dreyfus é que fenomenólogos "não tem muito a contribuir para os tópicos da estrutura lógica da intencionalidade ou a estrutura lógica da realidade social e institucional" (SEARLE, 1999, 11) é tentador concluir que ele não sabia realmente sobre o que estava falando.

\section{Empatia, contágio emocional e compartilhamento emocional}

Como já indicado, eu penso que a investigação da intencionalidade coletiva e da realidade social, isto é, tópicos tradicionalmente discutidos em ontologia social, pode e deve beneficiar-se com os resultados encontrados na discussão e exploração da cognição social. Deixe-me começar destacando algumas distinções entre contágio emocional, empatia e o compartilhamento emocional, que se mostrarão úteis.

Na discussão contemporânea da empatia, permanece uma questão de controvérsia como entender exatamente a relação entre contágio emocional e empatia. 
Assim, enquanto Eisenberg tem argumentado que empatia e contágio emocional são uma questão de simplesmente sentir a mesma emoção como o outro de um modo que, em orientação, não é nem altamente envolvido-a-si, nem direcionado-para-o-outro (EISENBERG, 1986, 31), Darwall tem afirmado que contágio emocional constitui a forma mais primitiva de empatia e que o mimetismo é um de seus mecanismos centrais (DARWALL, 1998, 264-266). Para outros, por contraste, tem se provado necessário optar por uma definição mais restrita de empatia que permita preservar as distinções entre empatia, por um lado, e contágio emocional, por outro (DECETY et al. 2008, de VIGNEMONT \& SINGER 2006). Tem sido argumentado, por exemplo, que contágio emocional é "auto-centrado"(self-centered), enquanto que empatia é essencialmente "centrada-no-outro" (other-centered) (de VIGNEMONT, 2009).

A mais recente visão sobre o assunto é a que também encontramos nas análises fenomenológicas clássicas da natureza e da estrutura da empatia. Considere, para tomar dois exemplos de Scheler, a situação na qual você entra em um bar e é tomado pela atmosfera agradável ou o caso em que você se encontra em um cortejo fúnebre e seu humor despenca. Um aspecto distintivo do que é conhecido como contágio emocional (Gefühlsansteckung) é que você literalmente captura a emoção em questão (SCHELER, 2008, 15). Ela é transferida para você. Ela se torna sua própria emoção e é vivida em primeira pessoa por você. No contágio emocional, o sentimento pelo qual você é infectado consequentemente não é fenomenalmente dado como estranho, mas como seu próprio (SCHELER, 2008, 73). Na verdade, quando infectado pela raiva, pânico ou jovialidade dos outros, você poderia nem mesmo estar ciente dos outros como indivíduos distintos. Dado que eu experiencio a emoção como minha própria antes do que como nossa, o contágio emocional não deveria ser confundido com compartilhamento emocional. Ele não constitui ou equivale uma experiência-nós (we-experience). Da mesma maneira, contágio emocional deve também ser distinguido de empatia, dado que a última envolve um foco sobre o outro e ter consciência do outro (SHELER, 2008, 23, 64). Como Stein colocaria em sua dissertação, Zum Probleme der Einfühlung, de 1916, experienciar empaticamente, por exemplo, a emoção do outro, necessariamente difere do modo como você experienciaria a emoção se ela fosse sua própria. De fato, por meio de tal experiência empática eu estou ciente de que a experiência empatizada pertence ao outro. Isso é também porque Stein rejeita a perspectiva de que a empatia deveria fazer-nos experimentar a emoção que nós observamos no outro, ou que ela de algum modo envolveria a transmissão da experiência do outro para a própria mente. Theodor Lipps, que foi o primeiro a discutir empatia (ou 
Einfühlung) no contexto da cognição social, originalmente sugeriu que empatia poderia ser explicada como uma forma de imitação interna (uma sugestão que subsequentemente veio a ser bastante popular entre os simulacionistas) (LIPPS, 1907). Em resposta, Stein insiste que mesmo quando uma expressão observada levasse ao observador imitá-la, e mesmo se, como um resultado da ligação próxima entre expressão e experiência, o observador subsequentemente viesse a experienciar a emoção associada nele mesmo, isso apenas explicaria porque uma certa experiência ocorreu nele. Isso não ofereceria uma explicação de como o observador veio a compreender o outro. Pois alguém sentir algo por si próprio e alguém empaticamente compreender o que um outro está sentindo são duas coisas muito diferentes. O primeiro evento não implica, per se, nem conhecimento sobre a origem do sentimento, nem conhecimento sobre a similaridade entre os próprios sentimentos de alguém e aqueles do outro. De fato, isso de maneira alguma conduz, por si só, a uma compreensão da vida mental do outro (STEIN, 2008, 35-36, ver também GURWINTSCH, 1979, 24-25).

Para os fenomenólogos, empatia é o rótulo para nossa experiência da mente encarnada e expressiva do outro, uma experiência que ao invés de eliminar a diferença entre a experiência de si e a experiência do outro, toma a assimetria como sendo um fato existencial necessário e persistente. Enquanto a experiência de empatizar é dada em primeira pessoa, a experiência empatizada não é dada em primeira pessoa para aquele que tem a empatia. Insistir que ela é, é desconsiderar o que é distintivo na empatia, a saber, o fato de que ela é uma forma de intencionalidade dirigida para o outro, que permite experiências alheias se abrirem elas mesmas como estranhas antes do que experiências próprias (HUSSERL, 1959, 176). Ainda mais importante, embora me falte acesso em primeira pessoa para a experiência empatizada - ela não é dada como minha, por exemplo, inquietação - não obstante é o caso de que a experiência empatizada é dada diretamente para mim como presente aqui e agora (STEIN, 2008, 5). Stein consequentemente contrasta empatia com uma compreensão cognitiva mais básica da experiência do outro que intenciona essa experiência sem compreendê-la diretamente. Poderia-se ilustrar a ideia em jogo do seguinte modo: exatamente como nós devemos respeitar a diferença entre pensar em um leão, imaginar um leão e ver um leão, nós também devemos respeitar a diferença entre referir-se (vagamente) à compaixão e amor de Emil, imaginar o que deve ser para ele se importar e amar, e ser empaticamente familiarizado com sua compaixão e amor no encontro direto cara-a-cara. No último caso, nosso contato com a vida experiencial de Emil é caracterizado por ser direto e possuir certa imediaticidade de tal maneira que não é compartilhado por quaisquer crenças que eu possa ter 
Você, eu e nós: o compartilhamento de experiências emocionais tradução de

Gabriel Henrique

Dietrich

sobre ele em sua ausência. Nós podemos também expressar isso dizendo que a empatia fornece um tipo especial de conhecimento por meio de um contato com o outro distinto - ao invés de contato em primeira pessoa. Por mais que empatia possa fornecer um tipo especial de compreensão, isso não significa que empatia forneça um tipo especialmente profundo ou penetrante de compreensão. De modo a obter isto, também se necessitaria inferências teoréticas e simulações imaginativas. A especificidade do acesso empático é antes devido ao fato de que ele é básico e intuitivo, isto é, a experiência empatizada é dada diretamente como existindo aqui e agora. ${ }^{1}$

Dada sua insistência sobre a diferença entre empaticamente compreender o que outro está experienciando e ter aquela mesma experiência para si, não deveria surpreender que os fenomenólogos rejeitariam a sugestão amplamente difundida de que empatia envolve um compartilhamento de experiência. Empaticamente compreender que seu amigo ama a esposa dele é muito diferente do que você mesmo amá-la. Isso não exige que você compartilhe o amor dele por ela. Do mesmo modo, você poderia empaticamente compreender a alegria de seu colega quando ele ouve a notícia de sua promoção, apesar de você estar pessoalmente desapontado com tal notícia. O fato de que você não compartilha a alegria dele, o fato de que você está sentindo uma emoção muito diferente, não faz de sua experiência um caso de menor empatia; isso não faz com que sua consciência da alegria dele seja de caráter meramente imaginativo ou inferencial. Além disso, diferente de um compartilhamento propriamente dito, para o qual reciprocidade é defensavelmente uma clara exigência, a empatia não tem de ser recíproca. Afirmar que nós compartilhamos uma experiência e que isso é algo em relação ao qual você permanece não-ciente é algo que não parece fazer muito sentido. ${ }^{2}$

Nem contágio emocional, nem empatia equivalem a uma experiência-nós (we-experience). Mas compartilhamento emocional, o que Scheler chama 'Mitfühlen' ou 'Miteinanderfühlen', pode ser um candidato mais promissor. Scheler nega que compartilhamento emocional possa ser compreendido como experiência individual mais conhecimento recíproco, isto é, ele nega que isso possa ser compreendido com a seguinte formulação: independentemente de cada um, $\mathrm{o}$ indivíduo A tem uma experiência emblemática do tipo $\mathrm{x}$, o indivíduo $\mathrm{B}$ tem uma experiência emblemática do tipo $\mathrm{x}$ e, além disso, cada um deles tem conhe-

1 Para uma discussão mais extensa do tratamento fenomenológico da empatia e sua relação com tópicos do trabalho contemporâneo em cognição social, ver Zahavi 2010, 2014 e, especialmente, 2014b.

2 Considere, por comparação, o caso onde eu desfruto de algum de seus Ardbeg Uigeadail toda vez que fico a sós em seu escritório, sem que você esteja ciente disso. Pretender que neste caso nós compartilhamos a garrafa de uísque parece um pouco forçado. 
cimento do outro. Mas, então, o que poderia resultar de um tratamento positivo do compartilhamento emocional? Para adotar alguns dos termos de condição, recentemente propostos por Szanto, compartilhamento emocional tem uma exigência de pluralidade, bem como uma exigência de integridade (SZANTO, 2015). Compartilhar não tem nada a ver com fusão, nem com uma unidade diluída. Compartilhar envolve uma pluralidade de sujeitos, mas ela também envolve mais do que mera soma ou agregação. Mesmo se dois indivíduos por coincidência tivessem o mesmo tipo de experiência, isso não equivaleria a uma experiência compartilhada. Apesar da similaridade das duas experiências, elas não seriam integradas da maneira requisitada. Contraste com isso uma situação onde um casal está assistindo um filme juntos. Não apenas cada um deles percebe e aproveita o filme, mas eles também experienciam que o outro está atento a e aprecia o filme, que é algo que afeta a estrutura e qualidade de seu próprio apreciar. Em resumo, o que indivíduos sentem quando eles fazem isso juntos não é independente da relação que eles têm um com o outro. Nós estamos lidando com experiências emocionais que, antes do que serem meramente independentes uma da outra, são co-reguladas e constitutivamente interdependentes.

Deve estar claro que a interdependência constitutiva em questão equivale a mais do que mera interdependência causal. Para algo ser considerado um caso de compartilhamento emocional, não basta dar-se inconscientemente, mas tem de envolver algum elemento de reconhecimento recíproco. Mas algo está faltando, mesmo após enfatizar esta "exigência de reconhecimento". Afinal de contas, não é difícil pensar casos de aspectos constitutivamente interdependentes de emoções, mas que apesar disso não são qualificadas como compartilhadas. Considere, por exemplo, o caso de um estuprador sádico cujo prazer alimenta-se, e é constitutivamente dependente, do terror da vítima e vice-versa. Dois indivíduos poderiam consequentemente estar cientes de sua interação emocional, sem ter compartilhado experiências. $\mathrm{O}$ que parece estar faltando é algum tipo de vínculo ou conexão afetiva, algum tipo de unificação ou identificação de um com o outro, o que Walther chamou de um sentimento ou sentido de estar-junto (togetherness) (Gefühl der Zusammengehörigkeit) (WALTHER, 1923, 33). Compartilhamento emocional deve encompassar, como Jessica e Peter Hobson colocam isso, "o outro como participante, comigo, naquela experiência" (HOBSON \& HOBSON, 2014, 188). Afinal de contas, no caso de, por exemplo, alegria compartilhada, a alegria não é mais simplesmente experienciada por mim como minha, mas como nossa. É por isso que faz perfeito sentido articular a experiência em questão com o uso do pronome 'nós': 'nós apreciamos o filme', 'nós estávamos tão assustados'. 
É claro que há muitos usos para o plural da primeira-pessoa. Em alguns casos, a locução "nós vimos o porco-espinho" poderia implicar nada mais do que um objeto comum. Se cada um de nós viu um porco-espinho em diferentes pontos do tempo ou ao mesmo tempo, mas sem saber da presença um do outro, nós podemos, sem qualquer perda, substituir "nós vimos o porco-espinho" por "eu vi o porco espinho e você viu o porco-espinho". Mas em outros casos, nós dizemos 'nós' de modo a expressar e o fato de sermos, e nossa identificação como, membros de um grupo (CARR, 1986a, 525). Tome, por exemplo, o caso onde meu filho e eu retornamos de uma viagem e, quando enxergamos um amigo em comum, eu grito 'nós vimos! Nós encontramos um porco-espinho!'. Neste caso, a experiência não é simplesmente dada a mim como minha experiência, mas como nossa; a ação não está simplesmente dada para mim como minha ação, mas como nossa ação. Se nós encontramos o porco-espinho juntos, e se cada um de nós estava ciente de que o outro também estava vendo-o, algo importante seria perdido pela reformulação distributiva, uma vez que o uso do 'nós' visava capturar mais do que simplesmente o fato de que havia um objeto comum. Nós encontramos o porco-espinho juntos, e embora eu não tenha visto o animal através dos olhos de meu filho, este ter sido visto por ele é parte da experiência que eu tive.

Embora a referência de Walther a um "sentimento de estar-junto" possa fornecer um título apto para o ingrediente faltante no compartilhamento emocional, ainda nos falta uma compreensão real do que possa ser esse tal sentimento. Para progredir, deixe-nos avançar e considerar alguns dados relativos à atenção conjunta e a adoção de perspectiva.

\section{A perspectiva em segunda-pessoa}

É amplamente difundido o consenso de que atenção conjunta não é simplesmente uma questão de duas pessoas simultaneamente olhar para a mesma coisa, nem é suficiente que a atenção delas seja causalmente influenciada pela direção da linha de visão da outra, um fenômeno que pode ser observado em cães, cabras e corvos. Para a atenção conjunta ocorrer, o foco atencional de duas (ou mais) pessoas não deve meramente dar-se paralelamente; ele deve envolver a consciência de assistir juntos, isto é, o fato de que ambas as pessoas prestam atenção ao mesmo objeto deve, para usar a expressão de Sperber e Wilson (1986), "mutuamente manifestar-se". Isto é o que precisamente faz a atenção conjunta muito diferente de qualquer tipo de experiência que se poderia ter por si mesmo. 
Posto em termos desenvolvimentais, instâncias exemplares de atenção conjunta não apenas incluem casos nos quais a criança está passivamente seguindo o foco de atenção de outro, mas também casos em que a criança, por meio de atos proto-declarativos, ativamente convida o outro a compartilhar seu próprio foco de atenção. Algumas vezes tem sido afirmado que crianças falham em apreciar a característica de diferentes sujeitos da experiência, e que a consciência delas de estados mentais envolve um nós indiferenciado, que não é passível de decomposição em um eu e você. Se com isso se pretende que a compreensão, por parte de infantes, das propriedades psicológicas de outros é tal que não há espaço para qualquer divergência entre o ponto de vista da criança e o ponto de vista de outro, a atenção conjunta inicial nos infantes fornece, como Roessler tem salientado, clara contra-evidência, uma vez que o ponto das proto-declarativas é precisamente trazer o foco de atenção de outro para junto de seu próprio foco de atenção (ROESSLER, 2005, 247).

Quando se exemplifica formas de atenção conjunta, há uma tendência em focar em triangulações que envolvem um objeto externo, mas por meio disso se negligencia um tipo diferente, diádico, de atenção conjunta, a saber, o encontrar-se em intercâmbios cara-a-cara, onde ambos os indivíduos sentem a atenção do outro (REDDY, 2008). Em várias publicações relativas ao desenvolvimento cognitivo-social na infância, Rochat tem salientado a importância deste intercâmbio diádico e defendido que o compartilhamento emocional já ocorre quando o infante tem por volta de seis semanas de vida. A partir daí, a criança e o seu cuidador começam a compartilhar ao co-construir experiências em interações diáticas cara-a-cara. Rochat enfatiza o papel do turnar-se rítmico com o outro e olhar mútuo para este processo de intercâmbio social proto-coversacional (ROCHAT, 2014), e tem também argumentado que o "ecoar dos afetos, sentimentos e emoções que ocorre na interação recíproca entre infantes e seus cuidadores" é um "elemento necessário para o desenvolvimento da cognição social mais avançada, incluindo a teoria da mente" (ROCHAT \&STRIANO, 1999, 8). Na verdade, sugere-se que infantes aprendam sobre seu mundo social não "a partir do 'dele' ou 'dela' que observam imparcialmente exteriormente", mas desde o 'vocês' com o qual eles interagem e engajam em atividades colaborativas com objetivos comuns e atenção compartilhada" (MOLL E MELTZOFF, 2012, 398).

Uma das coisas que deveria estar clara com estas breves observações é que atenção conjunta exige tanto 'co-ordenação' quanto diferenciação. Não há unidade difundida aqui, mas antes uma pluralidade preservada. O mesmo mantém-se verdadeiro para o compartilhamento emocional. Ele retém, ao invés de 
abolir, a diferença entre o si mesmo (self) e o outro. O que ainda necessita ser melhor compreendido, entretanto, é o tipo de relação que deve haver entre o si e o outro de modo a possibilitar o compartilhamento propriamente dito. Eu tenho argumentado que regulação e interdependência (temporalmente em curso) são fatores cruciais. O que agora está sendo enfatizado é também a significância da atenção diática e da tomada de perspectiva em segunda pessoa. Mas por quê esta última deveria fazer diferença?

Nos últimos anos, tem havido uma discussão contínua sobre se as duas principais posições dominantes no debate da teoria da mente, a teoria-teoria (em suas diferentes versões) e a teoria da simulação (em suas diferentes versões), são exaustivas e adequadas, quando se trata de capturar formas fundamentais de cognição social. Ocasionalmente argumenta-se que uma limitação de ambas as posições tradicionais é que elas privilegiam ou a perspectiva em primeira pessoa (o que a teoria da simulação faria) ou a perspectiva em terceira pessoa (o que faria a teoria-teoria) e que o que realmente necessitamos é uma teoria que explicitamente vise a perspectiva em segunda pessoa. Entretanto, há ainda alguma discordância sobre o que exatamente a tomada de perspectiva em segunda pessoa envolve. Um tratamento influente pode ser encontrado em um artigo, Ciências comportamentais e do Cérebro, escrito por Schilbach e colegas. Para eles, a perspectiva em segunda pessoa envolve a questão de diretamente interagir e engajar emocionalmente com outros (antes do que simplesmente observá-los desde uma distância). Assim, a perspectiva em segunda pessoa é contrastada com aquilo que é chamado a postura espectadora (SCHILBACH et al, 2013). Um aspecto que pode não ter sido suficientemente enfatizado no artigo acima, entretanto, é o papel da reciprocidade. Talvez o aspecto mais específico da perspectiva em segunda pessoa não é a parte da ação, não é o fato de que se está ciente dos estados mentais de outros como resultado de engajar e interagir com eles, mas é, antes, a questão da reciprocidade (DE BRUIN et al, 2012, FUCHS, 2012). Desde um tal tratamento, a perspectiva em segunda pessoa envolve uma relação recíproca entre você e eu, no qual o aspecto específico de relacionar-me com você como você é que você também tem uma perspectiva em segunda pessoa sobre mim, isto é, você me toma como o seu você (you take me as your you). Nessa medida, não pode haver um único você: tem de haver sempre pelo menos dois. Em resumo, adotar a perspectiva em segunda pessoa é engajar em uma relação sujeito-sujeito (você-eu) onde eu estou ciente do outro e, ao mesmo tempo, implicitamente ciente de mim mesmo no acusativo, como visado ou abordado pelo outro (HUSSERL, 1973a, 211). 
Ora, certamente esta idéia precisa ser desdobrada. Mas minha sugestão básica é que, se nós desejamos obter uma melhor compreensão do compartilhamento emocional e da experiência-nós que ele exemplifica, nós devemos olhar mais de perto o você, uma vez que a segunda pessoa do singular pode ser crucial para uma compreensão da primeira pessoa do plural. Compartilhamento emocional de fato pressupõe estar ciente do outro, mas tem de ser uma forma distinta de estar ciente do outro. Se duas pessoas adotam uma perspectiva em terceira pessoa uma em relação à outra, então mesmo se elas têm experiências constitutivamente interdependentes, elas não estarão empreendendo uma experiência compartilhada, uma vez que a exigida característica de estar-junto (em con-junto) estaria ausente. Mas por que alguma coisa mudaria ao se tomar a perspectiva em segunda pessoa?

Compartilhamento emocional exige a preservação da pluralidade e uma certa diferenciação de si-outro, mas, se a diferença entre o si e o outro é tão saliente, ela impedirá qualquer experiência de estar-junto. É necessário um balanço correto entre diferença e similaridade. Isso é o porquê você não pode partir de sua própria experiência de si corriqueira e exclusivamente em primeira pessoa, se você quer participar e juntar-se em uma experiência-nós. O que se necessita é uma certa parcela de auto-alienação - reduzir sua distância dos outros, e fazer-se mais como eles. Você precisa experienciar a perspectiva dos outros sobre você, você necessita estar ciente deles como estando cientes de você e ver você mesmo através dos olhos deles, tanto que você possa vir a experienciar você mesmo da maneira como você os experiencia. Quando isso acontece, você pode tornar-se ciente de si mesmo como um deles, ou, mais precisamente, você pode se tornar ciente de si mesmo como um de nós. É este processo que Husserl está descrevendo quando ele escreve que eu vim colocar-me a mim mesmo na família do homem, e criar a possibilidade da unidade desta família, quando eu compreendo os outros como apreendendo-me do mesmo modo como eu os apreendo. E, como ele então argumenta, é apenas assim que eu sou, pela primeira vez e em sentido próprio, um eu defronte a (over against) um outro e, por meio disso, em uma posição de dizer nós (HUSSERL, 1952, 242,250). Embora a descrição de Husserl do processo possa fazê-lo parecer demasiado complicado, não é obvio que estamos lidando com um processo que ocorre apenas no desenvolvimento tardio. Ou, para pôr em outros termos, não devemos esquecer que a forma mais avançada de tomar perspectiva em segunda pessoa tem precursores desenvolvimentais. Ao longo dos anos, Peter Hobson tem argumentado que o processo de 'identificar-com' desempenha um papel bastante central e primitivo no desenvolvimento humano ao estruturar a "experiência social com polari- 
dades de diferenciação do 'si-outro' bem como conectividade" (Hobson 2008: 386). Em um artigo co-autoral, o processo em questão é descrito da seguinte maneira: "identificar-se com alguém diferente é relacionar com as ações e atitudes deste outro alguém a partir da perspectiva ou postura do outro, de um tal modo que uma pessoa assimila a orientação do outro para o mundo, incluindo para si, tanto que esta orientação torna-se um aspecto do próprio repertório psicológico da pessoa" (HOBSON \& HOBSON, 2007, 415). É importante salientar que Hobson também considera identificar-com como estando crucialmente envolvido no compartilhamento afetivo, e ele argumenta que o engajamento afetivo de infantes, em seus primeiros anos, com outros já lhes proporciona experiências interpressoais que englobam uma interação entre similaridade e diferença, conectividade e diferenciação (HOBSON, 2007, 270, cf. REDDY, 2008).

Para ilustrar a relevância destas considerações, considere a diferença entre ser membro objetivo de um grupo e ser parte de um nós. Alguém poderia por nascimento (ou direito) ser membro de um certo grupo (família, classe, nação, etnicidade etc.) desconsiderando se alguém se importa ou sabe disso, exatamente como os de fora poderiam considerar alguém como um membro de um grupo independentemente da própria perspectiva deste alguém sobre isso. Mas esse tipo de adesão ao grupo não equivale a um nós. O nós é um termo para um modo distinto de ser com e se relacionar com outros. Ele não é algo observado de fora, mas algo que eu experiencio a partir do interior. Ao adotarmos uma perspectiva-nós, não deixamos o ponto de vista em primeira pessoa para trás; antes, meramente trocamos sua forma singular por sua forma plural (CARR, 1986a, 530). Para se tornar parte de um nós, o eventual membro tem que se identificar com o grupo. É atitude deles em relação a cada um (e em relação a eles mesmos) que importa. (CARR, 1986 b, 161). Isso não é dizer que a identificação com e a participação em um nós sempre aconteça voluntariamente. $O$ ponto é meramente que, de maneira importante, isso envolve, mais do que desvia, a auto-compreensão e perspectiva em primeira pessoa das partes envolvidas.

Como já indicado, alguma dessas ideias já poderiam ser encontradas na fenomenologia clássica. Em vários manuscritos, Husserl argumenta que algo notável, algo que vai além da empatia, acontece quando eu me volto para e começo a visar o outro. Como Husserl formula, quando procuro influenciar o outro, e o outro está ciente de que está sendo visado e corresponde, e quando ambos de nós nos tornamos cientes que nós estamos sendo experienciados e compreendidos pelo outro, nós estamos lidando com atos comunicativos através dos quais uma unidade interpessoal superior, um nós, é estabelecida, e por meio da qual o mundo adquire o caráter de um mundo verdadeiramente social (HUSSERL, 
$1973 b, 472 ; 1952,192-194)$. Husserl consequentemente enfatiza a centralidade da comunicação e diálogo e também destaca a importância da reciprocidade quando diz respeito à emergência do nós.

Ideias similares podem ser encontradas em fenomenólogos posteriores, tal como Schutz:

Eu assumo uma orientação-para-o-outro em direção ao meu parceiro, que por sua vez está orientado para mim. Imediatamente, e ao mesmo tempo, compreendo o fato de que ele, por sua parte, está ciente de minha atenção sobre ele. Em tais casos eu, você, nós, vivemos na relação social ela mesma, e isto é verdade em virtude da intencionalidade dos atos vividos dirigidos para o parceiro. Eu, você, nós somos por meio disso trazidos de um momento para o próximo em uma particular modificação atentiva do estado de ser mutuamente orientado um para o outro. A relação social na qual vivemos é constituída, portanto, por meio da modificação atentiva empreendida por minha orientação-para-o-outro, como eu imediata e diretamente compreendo no interior da própria realidade vivida do parceiro como alguém que por sua vez está orientado para mim. (SCHUTZ 1967: 156-157).

Quando vivemos em uma relação-nós, há um engajamento mútuo onde imediatamente afetamos um ao outro. Nesse ponto, Schutz inclusive escreve que nós estamos 'vivendo em nosso fluxo comum de consciência' (SCHUTZ, 1967, 167). Ao contrário de implicar uma fusão metafísica, o que Schutz tem em mente aqui é o fato de que nosso fluxos respectivos de consciência são interligados de tal maneira que cada uma das nossas respectivas experiências é colorida por nosso envolvimento mútuo (SCHUTZ, 1967, 167, 180). Além disso, Schutz insiste que a relação-nós ela mesma não é compreendida reflexivamente no interior da situação cara-a-cara. Antes do que ser tematicamente observada, se vive pré-reflexivamente através dela (SCHUTZ, 1967, 170). E se desejamos pensar e tematicamente observar nossa relação e experiências que temos juntos, nós devemos retrairmo-nos um para o outro e por meio disso sair da relação cara-a-cara (SCHUTZ, 1967, 167). Pode auxiliar relembrar aqui a diferença entre o que é geralmente denominado ‘ser-para-um-outro' (Füreinandersein) e ser-um- 
-com-o-outro (Miteinandersein). Enquanto a relação você-eu pode ser diádica, o nós muitas vezes envolve uma estrutura triádica, onde o foco está no objeto ou projeto compartilhado. Não apenas pode haver casos de interação você-eu intensas, tais como discordâncias verbais ou discussões fortes, onde não há ainda (ou não há mais) um nós presente, mas, mesmo em situações mais conciliatórias, dar demasiada atenção ao outro pode romper a perspectiva compartilhada. O casal que está assistindo o filme juntos pode servir como uma boa ilustração disso. Seu foco de atenção está no filme, e não um no outro. Entretanto, isso não é dizer que o compartilhamento emocional é independente e precede qualquer tomada de consciência do outro em segunda-pessoa. Nós não devemos cometer o erro de equivaler consciência com consciência temática ou consciência focal. Afinal de contas, eu posso permanecer ciente de meu parceiro, mesmo se eu não estou tematicamente ciente dele, e dificilmente faria sentido a noção de experiências compartilhadas, se a consciência de outro estivesse inteiramente ausente.

\section{Considerações Finais}

Recentemente, Hans-Bernhard Schimid argumentou que o compartilhamento emociona,1 de modo algum, pressupõe o dar-se do outro experenciador, mas antes precede qualquer dar-se deste tipo. Falando em termos mais gerais, ele nega que o nós seja fundado sobre uma experiência-do-outro ou que, de qualquer outro modo, envolva ou pressuponha algum tipo de relação recíproca entre eu e você, ego ou outro. A partir desta abordagem, aquilo que é compartilhado, aquilo que pertence a nós, precede a distinção entre seu e meu e é anterior a qualquer forma de intersubjetividade ou reconhecimento mútuo (SCHIMID, $2005,145,149,296)$. O contraste com a presente proposta deveria ser óbvio. Para o tratamento que estou propondo, a experiência-nós não é anterior ou equiprimordial com experiência-de-si ou experiência-do-outro. Antes, casos paradigmáticos de intencionalidade-nós pressupõe empatia (no sentido de intencionalidade dirigida-para-outro), e envolvem experiências constitutivamente interdependentes e o assumir a perspectiva em segunda pessoa. A diferenciação si-outro, a distinção entre si e outro, consequentemente precede a emergência e é retida no nós. Deixe-me enfatizar que esta não é uma afirmação redutiva. A afirmação não é que o nós possa ser reduzido ou abordado exaustivamente por meio de uma análise da relação você-eu. A afirmação é meramente que a relação você-eu é um componente necessário. Que ela não é suficiente pode ser 
Você, eu e nós: o compartilhamento de experiências emocionais

mostrado ao se considerar o exemplo de duas pessoas que estão tendo uma discussão acalorada e que por sua vez estão insultando uma à outra. Elas poderiam ter adotado uma perspectiva em segunda pessoa em relação uma à outra e ter emoções constitutivamente interdependentes, e ainda assim falhar em constituir um nós. Salmela recentemente destacou a importância das preocupações e valores compartilhados (SALMELA, 2012). Uma possibilidade seria defender que elas constituem outro ingrediente necessário. Entretanto, embora o tratamento oferecido permaneça de algum modo incompleto - por apenas especificar alguns dos componentes necessários - suficiente têm sido dito para responder à questão posta no início, a saber, se a experiência-nós pressupõe, precede, preserva ou abole a diferença entre a experiência de si e a experiência do outro.

Até aqui, entretanto, eu tenho focado exclusivamente no tipo de nós que emerge na interação cara-a-cara e que promove uma sensibilização em relação ao outro como indivíduo distinto. Mas se deve reconhecer que esta forma efêmera do nós, que é vinculada com o aqui e agora, é apenas um tipo de nós. Podemos, por exemplo, encontrar formas mais impessoais, anônimas e linguisticamente mediadas de intencionalidade-nós e identidade-nós. Considere, por exemplo, o caso em que um físico declara "nós finalmente descobrimos uma partícula bóson de Higgs" embora ele próprio não estivesse de maneira alguma diretamente envolvido com o experimento no CERN, ou o combatente que, quando encarando o pelotão de fuzilamento, grita "nós os derrotaremos!", que por meio disso identifica-se com um grupo que pós-datará sua própria existência. Pessoas podem experiênciar elas mesmas como membros de um grupo, podem identificar-se com outros membros do mesmo grupo, e podem vir a ter experiência que elas não teriam de outro modo, mesmo se elas não estão efetivamente (de facto) juntas de outras. Seria importante determinar aqui que papel vários processos desempenham em tais formas de intencionalidade 'nós', bem como se essas formas mais impessoais da intencionalidade-nós são simplesmente parasitárias da forma supostamente mais básica e fundamental da experiência-nós baseada no cara-a-cara, ou se elas tem sua própria originalidade e irredutibilidade. ${ }^{3}$ Neste ponto, entretanto, se poderia argumentar que há formas de intencionalidade-nós que são mais primordiais do que aquelas nas quais tenho focado. Considere, por exemplo, formas de ação coordenada que

3 Mesmo se o primeiro fosse o caso, isso não implicaria que alguém necessariamente teria de ter tido relações concretas você-eu com todos aqueles indivíduos que são membros do grupo com o qual alguém se identifica. $\mathrm{O}$ ponto seria antes que alguém teria tido algumas relações você-eu antes que pudesse engajar-se em formas mais anônimas de intencionalidade-nós. Do mesmo modo, embora assumir perspectiva em segunda pessoa possa ser o que em primeiro lugar conduz à auto-alienação, obviamente isto não significa negar que alguém possa subsequentemente, através de uma internalização da perspectiva de outro, vir a adotar uma perspectiva alienante sobre si mesma, mesmo quando ninguém mais está presente. 
tomam lugar indepentemente de qualquer intencionalidade dirigida-para-o-outro ou planos conjuntos, como quando agentes começam a agir como um único ente, porque eles são movidos pelos mesmos estímulos perceptuais e rotinas motoras. Exemplos que me vem a mente são casos onde uma audiência aplaude em uníssono, onde pedestres se encaixam no mesmo padrão de caminhada, ou onde duas pessoas em cadeiras de balanço involuntariamente sincronizam suas frequências de balançar (KNOBLICH et al., 2011). Se tal ação coordenada emergente se qualifica como uma forma de intencionalidade-nós, é duvidoso se ela pode ser analisada junto com as linhas sugeridas acima. Uma resposta possível a esse desafio seria distinguir diferentes formas de intencionalidade-nós e simplesmente insistir que o tipo que tenho analisado anteriormente é irredutível a, e mais complexa que, aquela encontrada em ação coordenada emergente. Outra opção, para a qual estou consideravelmente mais inclinado, é conceder que coordenação emergente pode ser certamente básica e fundamental, mas insistir que ela tem mais em comum com um mimetismo motor e um contágio motor do que com compartilhamento genuíno e que, portanto, em última instância, ela não equivaleria ou não constituiria uma genuína experiência-nós.

Obviamente há muito mais a ser dito sobre o compartilhamento e o nós. Até aqui, tenho focado apenas sobre algumas emoções ao discutir compartilhamento emocional. Podem todas as emoções ser compartilhadas do mesmo modo, e pode um tratamento do compartilhamento emocional ser generalizado em um tratamento do compartilhamento experiencial? Além disso, considere a afirmação de Turner e colegas de que "é onde diferenças entre grupos tendem a ser percebidas como maiores que diferenças intra-grupos que tendemos a categorizar o si mesmo como 'nós' ao invés de 'eu' e ver os outros incluídos como similar antes que diferentes" (TURNER et. Al., 1994, 457). Em resumo, qual é o papel do eles, e em que medida a tendência para experienciar a si mesmo como parte do nós, como um de nós, aumenta quando somos confrontados com membros de fora do grupo e de grupos contrastantes? Todas essas são questões importantes, mas questões que não posso perseguir aqui.

Eu espero ter mostrado que uma investigação do nós pode contribuir para uma exploração do você e eu, do si e do outro (ver também ZAHAVI, 2014b). Eu concordaria com aqueles que pretendem que resultados de outros domínios da ontologia social e da cognição social podem exercer pressão sobre certas assunções em filosofia da mente. Descobertas nos primeiros domínios poderiam nos forçar a revisar ou mesmo rejeitar certas abordagens completamente solipsistas e sem corpo da mente e do si mesmo (self), se o último deveria mostrar-se incompatível com a existência de fenômenos-nós genuínos. Eu concordo com 
Você, eu e nós: o compartilhamento de experiências emocionais tradução de

Gabriel Henrique

Dietrich

isso, mas eu rejeitaria a tentativa de que o caminho adiante, que viria para desenvolver um tratamento satisfatório do nós, abandonaria também noções como sujeito, subjetividade, eu, você, mim, si, outro. Fazer isso não seria apenas jogar fora o bebê proverbial com a água do banho ${ }^{4}$, seria também sugerir um comprometimento com a própria noção Cartesiana do sujeito que alegadamente se estava tentando superar ${ }^{5}$.

4Nota de tradução: Essa expressão idiomática anglo-americana se refere à necessidade de evitar descartar tudo junto, pela possibilidade de se perder algo valioso juntamente com o que não se quer mais. Provavelmente, é uma tradução adaptada proveniente de um provérbio alemão que diz: Das Kind mit dem Bade ausschütten.

5 Estou endividado para com dois revisores anônimos por seus comentários bastante úteis.

Recebido em: 09.02.2015 | Aprovado em: 20.02.2015

CARR, D. "Cogitamus Ergo Sumus: The Intentionality of the First-Person Plural'. In: The Monist, 69(4), 521-533, 1986a.

. Time, Narrative, and History. Bloomington: Indiana University Press, $1986 b$.

DARWALL, S. "Empathy, Sympathy, Care". In: Philosophical Studies, 89(2/3), 261-282, 1998.

DE BRUIN, L., van Elk, M., \& Newen, A. "Reconceptualizing Second-person Interaction'. In: Frontiers in Human Neuroscience, 6, 1-14, 2012.

DE VIGNEMONT, F. “Affective Mirroring: Emotional Contagion or Empathy?" In: S. Nolen-Hoeksema, B.

Frederikson, G. R. Loftus, \& W. A. Wagenaar (Eds.),
Atkinson and Hilgard's Introduction to Psychology (15th ed., p. 787). Florence, KY: Cengage Learning, 2009.

DE VIGNEMONT, F., \& SINGER, T. "The Empathic Brain: How, When and Why?". In: Trends in Cognitive Sciences, 10(10), 435-441, 2006.

DECETY, J., MICHALSKA, K. J., \& AKITSUKI, Y. "Who Caused the Pain? An Investigation of Empathy and Intentionality in Children". In: Neuropsychologia, 46(11), 2607-2614, 2008.

EISENBERG, N. Altruistic Emotion, Cognition, and Behaviour. Hillsdale, NJ: Lawrence Erlbaum, 1986.

FUCHS, T. The Phenomenology and Development of 
Social Perspectives. Phenomenology and the Cognitive Sciences, 2012.

GURWITSCH, A. Human Encounters in the Social World. Pittsburgh: Duquesne University Press, 1979.

HOBSON, R.P. Communicative Depth: Soundings from Developmental Psychopathology. Infant Behavior \& Development 30, 267-277, 2007.

. Interpersonally Situated Cognition. International Journal of Philosophical Studies 16(3), 377-397, 2008 .

HOBSON, J. A., \& Hobson, R.P. Identification: The Missing Link between Joint Attention and Imitation? Development and Psychopathology 19, 411-431, 2007.

HOBSON, R. P., \& HOBSON, J. “On Empathy: A Perspective from Developmental Psychopathology". In H. Maibom (Ed.), Empathy and Morality (pp. 172-192). Oxford: Oxford University Press, 2014.

HUSSERL, E. Ideen zu einer reinen Phänomenologie und phänomenologischen Philosophie. Zweites Buch. Phänomenologische Untersuchungen zur Konstitution. E. M. Biemel. Husserliana 4. Den Haag: Martinus Nijhoff, 1952.

. Erste Philosophie (1923/24). Zweiter Teil.

Theorie der phänomenologischen Reduktion. Ed. R. Boehm. Husserliana 8. Den Haag: Martinus Nijhoff, 1959.

. Zur Phänomenologie der Intersubjektivität

II. Texte aus dem Nachlass. Zweiter Teil. 1921-28. Ed.

I. Kern. Husserliana 14. Den Haag: Martinus Nijhoff, 1973a.

. Zur Phänomenologie der Intersubjektivität III. Texte aus dem Nachlass. Dritter Teil. 1929-35. Ed. I. Kern. Husserliana 15. Den Haag: Martinus Nijhoff. (1973b).
KNOBLICH, G., BUTTERFILL, S., \& SEBANZ, N. "Psychological Research on Joint Action: Theory and Data". In: B. H. Ross (Ed.), The Psychology of Learning and Motivation (pp. 59-101). Burlington: Academic Press, 2011.

LIPPS, T. "Das Wissen von fremden Ichen". In: T. Lipps (Ed.), Psychologische Untersuchungen I (pp. 694-722). Leipzig: Engelmann, 1907.

MOLL, H., \& MELTZOFF, A. N. Joint Attention as the Fundamental Basis of Understanding Perspectives. In A. Seemann (Ed.), Joint Attention: New Developments in Psychology, Philosophy of Mind, and Social Neuroscience (pp. 393-413). Cambridge, MA: The MIT Press, 2012.

REDDY, V. How Infants Know Minds. Cambridge, Mass.: Harvard University Press, 2008.

ROCHAT, P., \& Striano, T. Social-Cognitive Development in the First Year. In P. Rochat (Ed.), Early Social Cognition: Understanding Others in the First Months of Life (pp. 3-34). Hillsdale, NJ: Erlbaum, 1999.

. Origins of Possession: Owning and Sharing in Development. Cambridge: Cambridge University Press, 2014.

ROESSLER, J. Joint Attention and the Problem of Other Minds. In N. Eilan, C. Hoerl, T. McCormack, \& J. Roessler (Eds.), Joint Attention: Communication and Other Minds (pp. 230-259). Oxford: Oxford University Press, 2005.

SALMELA, M. Shared Emotions. Philosophical Explorations 15(1), 33-46, 2012.

SCHELER, M. The Nature of Sympathy. London: Transaction Publishers, 2008.

SCHILBACH, L., Timmermans, B., Reddy, V., Costall, A., Bente, G., Schlicht, T., \& VOGELEY, K. To- 
ward a Second-Person Neuroscience. Behavioral and Brain Sciences, 36(04), 393-414, 2013.

SCHMID, H. B. Wir-Intentionalität: Kritik des ontologischen Individualismus und Rekonstruktion der Gemeinschaft. Freiburg: Karl Alber, 2005.

.Plural Action: Essays in Philosophy and Social Science. Dordrecht: Springer, 2009.

SCHUTZ, A. Phenomenology of the Social World. Evanston, IL: Northwestern University Press, 1967.

SEARLE, J.R. Collective Intentions and Actions. In P. Cohen, J. Morgan, \& M.E. Pollack (Eds.), Intentions in Communication (pp. 401-416). Cambridge, MA: The MIT Press, 1990.

.The Construction of Social Reality. The Free Press, 1995.

"Neither Phenomenological Description nor Rational Reconstruction: Reply to Dreyfus". http:// socrates.berkeley.edu/ jsearle/articles.html (accessed July 2014), 1999.

SPERBER, D. and Wilson, D. Relevance: Communication and Cognition. Oxford: Blackwell, 1986.

STEIN, E. Zum Problem der Einfühlung. Freiburg: Herder, 2008.

SZANTO, T. Husserl on Collective Intentionality. In: A. Salice \& H.B. Schmid (eds.): Social Reality: The Phenomenological Approach. Dordrecht: Springer, 2015.

TURNER, J. C., OAKES, P. J., HASLAM, S. A., \& MCGARTY, C. "Self and Collective: Cognition and Social Context". In: Personality and Social Psychology Bulletin, 20(5), 454-463, 1994.

WALTHER, G. Zur Ontologie der sozialen Gemeinschaften. In E. Husserl (ed.), Jahrbuch für Philosophie und phänomenologische Forschung VI (pp. 1-158).
Halle: Niemeyer, 1923.

ZAHAVI, D. Empathy, Embodiment and Interpersonal Understanding: From Lipps to Schutz. Inquiry, 53(3), 285-306, 2010.

. (2014a). Empathy and Other-Directed Intentionality. Topoi 33(1), 129-142.

. Self and Other: Exploring Subjectivity, Empathy, and Shame. Oxford: Oxford University Press, 2014b. 